\title{
Amniotic bands in connective tissue disorders
}

\author{
I D YOUNG, R H LINDENBAUM, E M THOMPSON, AND M E PEMBREY \\ Department of Child Health, Leicester Royal Infirmary; Department of Medical Genetics, Churchill Hospital, \\ Oxford; and the Clinical Genetics Unit, Institute of Child Health, London
}

SUMmaRY Amniotic bands are described in two children with Ehlers-Danlos syndrome type IV and in one with severe osteogenesis imperfecta. Since the basic defect in both of these disorders rests in collagen, which constitutes the main component of the load bearing amnion, it is proposed that these cases provide further insight into the pathogenesis of amniotic bands.

Various theories have been forwarded to explain the pathogenesis of the amniotic band syndrome. Streeter's original proposal of a primary developmental defect in the germ disc and amniotic $\operatorname{sac}^{1}$ has been superseded by Torpin's theory of early amniotic rupture without injury to the chorion. ${ }^{2}$ The subsequent disruption of development in the embryo or fetus results from adherence of strands of amnion or chorionic mesenchyme. If amniotic rupture occurs before 45 days' gestation the results are likely to be devastating and may include severe skull defects such as anencephaly, facial clefts, and major visceral defects such as gastroschisis. ${ }^{3}$ After 45 days the effects tend to be limited to the limbs and may include ring constriction, amputation, and pseudosyndactyly.

In keeping with Torpin's theory of amniotic rupture, amniotic bands have been noted after amniocentesis ${ }^{4} 5$ and abdominal trauma. ${ }^{6}$ The three children we now describe provide further support for Torpin's theory. Each child had an amniotic band or bands in association with an inherited abnormality of connective tissue.

\section{Case reports}

Case 1. This boy was born at 30 weeks' gestation after spontaneous rupture of membranes at 29 weeks. His birthweight was $1540 \mathrm{~g}$. His 28 year old mother, who is described below, took no drugs during pregnancy, but was admitted at 24 weeks for investigation of abdominal pain for which no cause was found.

Apgar scores were 6 at one minute and 9 at five minutes. Abnormalities noted at birth included left calcaneovalgus and two constriction rings on the right leg. Apart from two short apnoeic episodes which responded to stimulation, there were no major problems in the neonatal period. On the 28th day of life, however, a rapidly increasing head circumference was noted along with xanthochromic cerebrospinal fluid and shortly afterwards a ventriculo-atrial shunt was inserted for hydrocephalus, presumed to have been haemorrhagic in origin.

On assessment at 2 years he was noted to show mild developmental delay with signs of mild cerebral palsy. He had a narrow face with a inin nose; thin skin with easily visible veins on the forehead, hands, and trunk; undescended testes; pronounced joint laxity at the wrists and fingers; and two constriction rings on the right leg (Figure).

The parents of this patient were unrelated. His father and older brother are healthy. His mother had a long history of medical problems beginning at her own delivery, which occurred prematurely at 32 weeks. Throughout life she bruised easily and had thin friable skin, as illustrated by the fact that on one occasion she required 20 stitches for a superficial cut sustained by a flower stalk. She always bled heavily after minor trauma and dental extractions, and had heavy periods. She was investigated for loin pain at age 24 years, pulmonary haemorrhage at 25 years, and retinal haemorrhage at 26 years. After each of her two deliveries she had an extensive perineal tear.

During life she was noted to be thin, with alopecia, gaunt facies, telangiectasia, thin skin, and acrogeria. She died suddenly aged 30 years a few hours after the acute onset of back pain. At necropsy a large retroperitoneal haematoma was noted in association with rupture of the right renal artery.

The parents of this lady were healthy and unrelated and she had 10 healthy older siblings. Her father was aged 43 years at the time of her birth. 


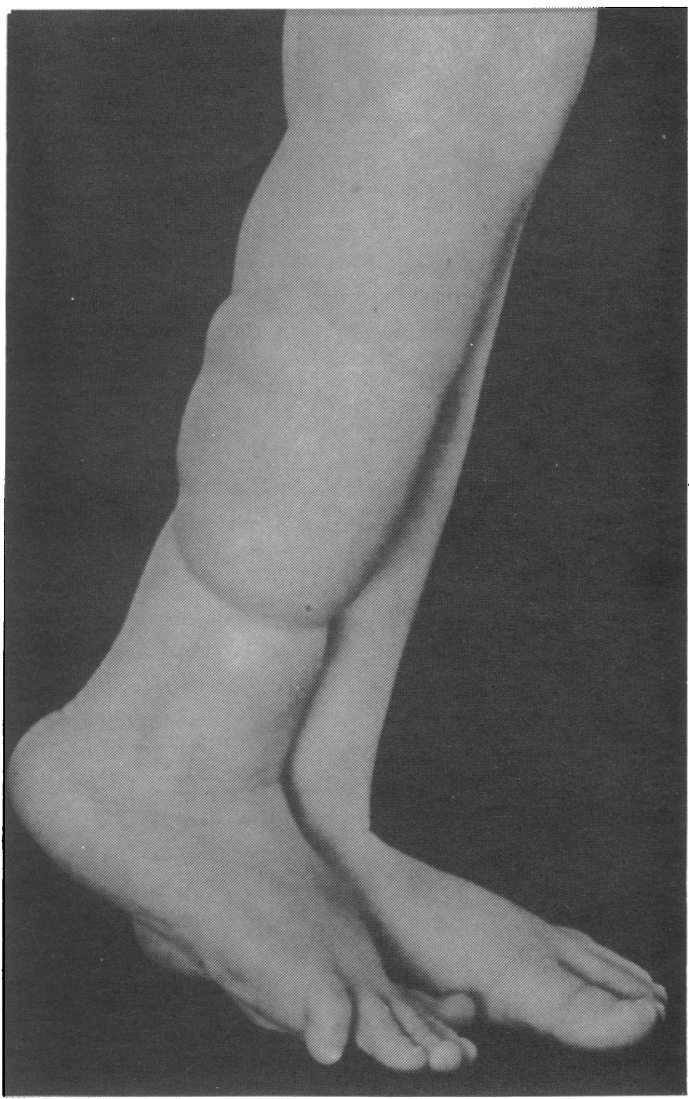

Figure Constriction rings on the right leg of case 1 at age 2 years.

Case 2. This boy was born weighing $1860 \mathrm{~g}$ at 33 weeks' gestation. During pregnancy his 26 year old mother had suffered persistent vomiting, ruptured varicose veins, and spontaneous rupture of the membranes at 32 weeks' gestation. The baby had no serious problems associated with prematurity, but was noted to have a fairly tight annular stricture (amniotic band) around the middle of the left forearm. There was no oedema and blood supply to the hand was well maintained. Other abnormalities noted at birth were hyperextensible fingers, a right talipes equinovarus, and undescended testes.

When seen at 8 months of age the left arm was functioning normally. His facial skin was tight around his nose and forehead as in his mother (see below). There was considerable bruising over his left eye where a camera had fallen on him eight weeks previously. At $3 \frac{1}{2}$ years he was reported to be growing and developing normally.

His parents were unrelated. His mother had also been born prematurely, weighing $1925 \mathrm{~g}$ at 34 weeks. Her colon ruptured spontaneously at 3 years of age and subsequent health problems included an intrapulmonary haematoma, two pneumothoraces, a carotidocavernous fistula after rupture of an aneurysm below the carotid syphon, and a ruptured bladder and uterus after obstetric instrumentation. As an adult she was noted to have a tight pinched face and prominent eyes with chemosis. Her skin was not hyperextensible but was thin with widespread bruising and scarring. Her hands were blotchy and showed acrogeria with hypermobile joints. She also had prominent varicose veins and osteoarthritis in both knees.

This lady was pregnant on four occasions, two pregnancies resulting in first trimester miscarriages and one ending at 26 weeks with the delivery of twins who both died. The parents of this lady were healthy and unrelated and she had three healthy sisters. Her father was aged 27 years at the time of her birth.

Case 3. This girl was born at 38 weeks' gestation in 1972 and died half an hour after birth. This was the mother's fifth pregnancy; the first resulted in a miscarriage at four months, the next three produced healthy children, one of whom, a girl, had bilaterally short 4th metacarpals. The mother was 40 years old at the birth of this child. The pregnancy was complicated by severe polyhydramnios. Delivery was by elective caesarean section for three prior caesarean sections and because the fetus was lying in a transverse position. At delivery, the amniotic fluid volume was estimated to be at least 31 , despite a recent amniocentesis performed to decrease the amount of liquor. The birthweight was $1560 \mathrm{~g}$, and the Apgar score was 2 at one minute. The child seemed abnormal, with a large, soft head and shortening of all four limbs with constriction rings (amniotic bands) at both wrists and at the left ankle. The right foot was absent. Spontaneous respiration was never established. A radiograph showed multiple fractures in most bones including all the ribs. The skull was very poorly ossified and the cortex of the long bones was very thin.

At necropsy the above findings were confirmed. The long bones were extremely soft. The following seemed macroscopically normal: brain, heart, lungs, mouth, oesophagus, pharynx, stomach, intestine, peritoneum, gall bladder, pancreas, spleen, lymph nodes, bone marrow, pituitary, thyroid, adrenals, kidneys, bladder, and genitalia. The liver was a little enlarged. Microscopic examination of the femur showed its cortex to be very poorly formed with a lack of characteristic normal lamella formation, consistent with osteogenesis imperfecta. Unfortu- 
nately, the radiographs and photographs of the patient were no longer available.

\section{Discussion}

This paper reports the presence of amniotic bands in three children with connective tissue disorders. In cases 1 and 2 the history and clinical findings in the boys and their mothers are consistent with the Ehlers-Danlos syndrome type IV, while case 3 had a severe lethal form of osteogenesis imperfecta.

It is probable that the basic defect in both of these disorders rests in collagen, type III in the EhlersDanlos syndrome type $\mathrm{IV}^{7} 8$ and type $\mathrm{I}$ in severe osteogenesis imperfecta. ${ }^{910}$ It is known that collagen types I, III, and V comprise the major constituents of the fetal membranes ${ }^{11}$ and that the amnion is the main load bearing component. ${ }^{12}$ There is also evidence that the amnion collagen content falls during the last few weeks of pregnancy in preparation for labour. ${ }^{13}$

Thus, in the three children described it is likely that the amniotic bands resulted from premature rupture of the amnion due to reduced or abnormal collagen in the amnion itself. This would be in keeping with the description of amniotic bands in a child with epidermolysis bullosa, ${ }^{14}$ at least one form of which results from increased collagenase activity, ${ }^{15}$ and in a fetus with severe osteogenesis imperfecta. $^{16}$

Complications in pregnancy are well recognised in type IV Ehlers-Danlos syndrome. ${ }^{17} 18$ These may include premature rupture of the fetal membranes leading to preterm delivery; rupture of maternal viscera including bowel, blood vessels and uterus; vaginal laceration; and postpartum haemorrhage. Maternal mortality may be as high as $25 \% .{ }^{18}$ The findings in cases 1 and 2 suggest that amniotic bands should be added to this alarming list of complications.

The findings in the three children described in this report provide further evidence to support Torpin's theory that amniotic bands result from premature rupture of the amnion. It would seem prudent to advise mothers carrying a fetus at risk of having a connective tissue disorder to pay particular attention to avoiding abdominal trauma. Similarly, careful consideration should be given to amniocentesis and fetoscopy in these pregnancies, since although these may be indicated for diagnostic purposes, each of these procedures may pose special hazards for the fetus.
We authors thank Dr J R Moore for referring case 1, Dr C R Martin-Bates for referring case 2, and Mrs Susan Kenney for typing the manuscript.

\section{References}

1 Streeter GL. Focal deficiencies in fetal tissues and their relation to intra-uterine amputation. Contributions to Embryology 1930;22:1-44.

2 Torpin R. Fetal malformations caused by amnion rupture during gestation. Springfield Illinois: Thomas, 1968.

3 Higginbottom MC, Jones KL, Hall BD, Smith DW. The amniotic band disruption complex: timing of amniotic rupture and variable spectra of consequent defects. $J$ Pediatr 1979;95:544-9.

4 Rehder H, Weitzel H. Intrauterine amputations after amniocentesis. Lancet 1978;i:382.

5 Moessinger AC, Blanc WA, Byrne J, Andrews D, Warburton D, Bloom A. Amniotic band syndrome associated with amniocentesis. Am J Obstet Gynecol 1981;141:588-91.

${ }^{6}$ Ossipoff V, Hall BD. Etiologic factors in the amniotic band syndrome: a study of 24 patients. Birth Defects 1977;XIII, 3d: $117-32$.

7 Pope FM, Martin GR, Lichtenstein JR, et al. Patients with Ehlers-Danlos syndrome type IV lack type III collagen. Proc Natl Acad Sci USA 1975;72:1314-6.

${ }^{8}$ Byers PH, Holbrook KA, McGillivray B, MacLeod PM, Lowry RB. Clinical and ultrastructural heterogeneity of type IV Ehlers-Danlos syndrome. Hum Genet 1979;47:141-50.

9 Barsh GS, Byers PH. Reduced secretion of structurally abnormal type I procollagen in a form of osteogenesis imperfecta. Proc Natl Acad Sci USA 1981;78:5142-6.

${ }^{10}$ Byers PH, Bonadio JF, Steinmann B. Osteogenesis imperfecta: update and perspective. Am J Med Genet 1984;17:429-35.

1 Pope FM, Nicholls AC, Dorling J, Webb J. Molecular abnormalities of collagen: a review. J R Soc Med 1983;76:1050-62.

12 Hoyes AD. Ultrastructure of the mesenchymal layers of the human amnion in early pregnancy. Am J Obstet Gynecol 1970;106:557-66.

13 Skinner SJM, Campos GA, Liggins GC. Collagen content of human amniotic membranes: effect of gestation length and premature rupture. Obstet Gynecol 1981;57:487-9.

14 Marras A, Dessi C, Macciotta A. Epidermolysis bullosa and amniotic bands. Am J Med Genet 1984;19:815-7.

15 Bauer EA. Recessive dystrophic epidermolysis bullosa: evidence for an altered collagenase in fibroblast cultures. Proc Natl Acad Sci USA 1977;74:4646-50.

16 Elejalde BR, de Elejalde MM. Prenatal diagnosis of perinatally lethal osteogenesis imperfecta. Am J Med Genet 1983;14:353-9.

17 Barabas AP. Ehlers-Danlos syndrome: associated with prematurity and premature rupture of foetal membranes; possible increase in incidence. Br Med $J$ 1966;ii:682-4.

18 Rudd NL, Nimrod C, Holbrook KA, Byers PH. Pregnancy complications in type IV Ehlers-Danlos syndrome. Lancet 1983;i:50-3.

Correspondence to Dr I D Young, Department of Child Health, Clinical Sciences Building, Leicester Royal Infirmary, PO Box 65, Leicester LE2 7LX.

Received 14 June 1985

An article by Buchanan and Wyatt on Marfan's syndrome presenting as an intrapartum death appears on $\mathrm{p} 1074$ of this issue. 